\title{
Geospatial Mashups: Internet Based Promotional Tool for Tourism Development
}

\author{
Somnath Chaudhuri ${ }^{1}$, and Dr. Nilanjan Ray $^{2}$
}

\begin{abstract}
Tourism has developed as a new form of service industry for alternative and sustainable socio-economic development of a country. Tourism industry has widely implemented Web based Geographic Information System, in order to improve information sharing, monitoring-planning and overall tourism and destination management. Geospatial Mashup is an interactive and collaborative Web 2.0 application that helps in integrating heterogeneous data from various resources to create internet based collaborative geospatial information system. This research paper focuses on the fact that, Geospatial Mashups have a huge potential in the field of tourism marketing and promotion. The current study also highlights on the basic architecture, working principles and effective implementation of Mashup technology in tourism industry.
\end{abstract}

Keywords- GIS, ICT, OGC, Web 2.0

\section{INTRODUCTION}

$\mathrm{T}$ OURISM is defined by the World Tourism Organization (NSCB, 2004), as the act of travelling for the purpose of recreation and the provision of services for this act. Tourism is a vital part of the global economy. Currently, this industry is one of the fastest growing industries all over the world. Tourism has some specific advantages over other industries like; it helps countries that are poor in material wealth but enriched in heritage, culture, history to utilize their unique characteristics as a revenue-generating source. It creates networks of different supporting operations like restaurants, hotels, transport services, guides, local small scale industries and many more. This business involves many socioeconomic activities like promotion and advertising tourist spots and destinations, providing effective transport facility, fooding-lodging, entertainment etc. which tends to encourage the overall development of infrastructures that benefits the host countries. This smokeless industry is essentially a kind of service industry; it renders service to the tourists [1]. Information and communication is an integral part of any service industry, tourism is not an exception. Information Technology breaks the geographical boundaries and share with the global audiences. It integrates between tourism products and requirement of the tourists. Information and Communication Technology (ICT) can lead tourism to emerge as a new mantra for alternative economic development [2]. Information technology is being rapidly diffused throughout the tourism industry and that no player will escape from

Somnath Chaudhuri ${ }^{1}$ is with the Faculty of Science, Maldives National University, Republic of Maldives.

Dr. Nilanjan Ray ${ }^{2}$ is with Netaji Mahavidyalaya, India. information technologies impacts. These technological innovations started in the 1970s when the main airlines set up CRSs (Computerized Reservation Systems), with the strategic aim of building a global distribution network for their products. Connecting travel agencies to the CRSs set off a process of distribution automation involving an everincreasing number of tour operators, carriers, and car hire firms, individual hotels, hotel chains, and other hospitality firms [1]. Geographical Information System (GIS), an ICT tool has been extensively used for tourism promotion and management. It was in use for GIS data design and collection, management of database design and application of tourism analysis and problem solving. Currently, Internet has become the inseparable part of the Information and communication technology. The GIS technicians and researchers started research on how to share the GIS features online, rather than using it as a standalone system. Since 1993, the Web GIS started evolving rapidly. The online static maps slowly changed to interactive dynamic maps over the World Wide Web. This is the first step of Web GIS. The greatest advantage was to get rid of traditional desktop GIS, its installation and data sharing hazard. Today's web user can create content on the web both collaboratively and individually, allowing for a personalized web experience through wikis, blogs, podcasts, photo sharing, and other technologies. GIS and mapping applications have both benefited from and contributed to these trends, collectively called "Web 2.0" [3]. This provides the concept of Geospatial Mashups. Integration of multiple data layers from varied sources, is one of the most common and effective functional requirements of Web GIS applications. On the Web GIS context, a Mashup is the process of merging multiple sources of data, both spatial and non-spatial, into a single integrated spatial display. It is about extracting spatial data from a non-spatial source and combining with other spatial data and finally displaying it on a map. Mashups can potentially combine any type of contents and functions over the web, regardless of whether a formal interface of programming is available [4]. The present study discusses the basic architecture of the Geospatial Mashups in Web GIS and its application in tourism promotion. 


\section{OBJECTIVES OF THE STUDY}

The principal objectives of the present study are:

- To identify the major challenges and issues of Web based Information and Communication technology in tourism development.

- To study the role of Web GIS in general and Geo-special Mashups in particular for analyzing destination image.

- To figure out major Geo-special architecture channels and recommend the application of it in various means for promoting tourist destination.

\section{BACKGROUND}

GIS is an information system that provides functions including visual presentation about the tourism destination, advanced analyses etc. of digital geospatial information by processing it in an integrated manner on electronic maps of tourist site [1]. The United States Geological Survey (USGS) defines, "GIS as a computer hardware and software system designed to collect, manage, analyze and display geographically (spatially) referenced data". But still it was standalone desktop software, not a web based application. Insert and update anomalies were at large. As the information sharing is not interactive or collaborative, there were difficulties in updating existing graphical information and maps online. More and more research works were going on to solve the problem of sharing the GIS features online. From the year 1993, the Web GIS started evolving rapidly. The online static maps slowly changed to interactive dynamic maps over the World Wide Web. This is the first step of Web GIS. In the year 2007, Fajuyigbe and Balogun presented a work on WebEnabled GIS as a potential tool for sustaining tourism in western Nigeria. It discusses how a Web-based GIS was used as a potential tool for the rendering and analysis of tourism information for the efficient management, promotion and sustainability of tourism in Nigeria [5]. Recently, a new term has been introduced to the Web Community: "Web 2.0". The principal aspect of this second generation web-based community is its interactive and collaborative feature. Another aspect of this Web as platform is sites which provide users with access to their data through well-defined Application Programming Interfaces (API) and hence encourage new uses of that data, for example through its integration with other data sources [6]. Today any web user can create or update content on the web both collaboratively and individually. But just embedding a video or an image on a web page is not a Mashup. Mashups gained a new meaning in the web application context in 2005 with the emergence of browserside APIs, attracting a surge of interest from both professional and casual GIS users [4]. In a true Mashup, the Mashup creator is free from having the overhead to host, update, customize and maintain data; instead he can focus on combining the data into new products or applications. A GIS or Map Mashup integrates a map source from Google Earth, Arc GIS, MS Virtual earth, or Open Layers, with data source from government databases or even from social sites like Facebook, Twitter etc. and creates a new application often using some APIs. There are few Mashup applications for small destination management organizations websites which try to implement innovative user-friendly interfaces for destination marketing and promotion. The project considers two areas to incorporate these new technologies on the same user interface: the official information about a destination provided by the destination management organizations; and user-generated content provided by consumers [6]. Zaragoza (Saragossa in English) is one of the cultural heritage centres and the fifth most populated city of Spain. The city council of Zaragoza has deployed a tourist promotional Mashup, named eZaragoza. It provides only tourism related information for both internal and external entities. It is using Linked Data, a public dataset as the core data base. The whole application is built on a Mashup platform called, $E z W e b$ where application components exchange information among them. This Mashup approach has proven useful in order to build end-user applications for exploring rich datasets of Linked Data. Reusability is possible at two complimentary layers [7]. Another popular Mashup example is HousingMaps.com. It integrates the data and services from Google Map and craigslist- a data source for local classifieds and forums for 567 cities worldwide [8]. Thus, Geospatial Mashup has great potential to facilitate and widen the rapid development of the future web mapping technology in tourism promotion and management.

\section{ICT TOOLS AND TOURISM MARKETING}

According to a current report by COMCEC on Effective Tourism Marketing Strategies, there are four active elements that have significant influence on ICT-based tourism marketing, as illustrated in Figure 1.

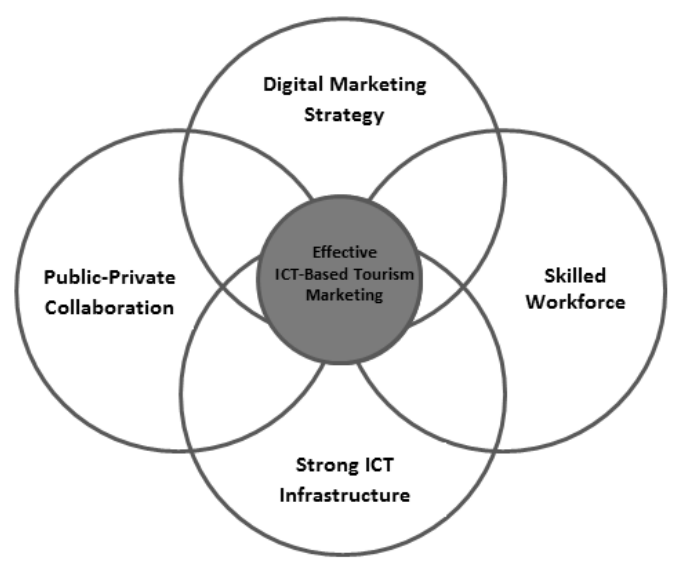

Fig. 1 Key Elements of ICT-based Tourism Marketing

Tourism marketing is most effective when it illustrates the composite experience of a destination and not simply a laundry list of attractions and accommodations [9]. The next section will highlight on some cost-effective and user-friendly ICT initiatives for tourism marketing.

Brand Strategy: In any industry, a group of customers rely on the brand name. Tourism being a service industry, its brand lies in the service quality and its promise. Brand value and brand promise create positive associations between the destination or company's quality assets and the potential 
tourist. ICT based tourism marketing has an effective role in extending the brand and creating brand equity.

Content Development and Management: Adequate information about a product is one of the key features of promotion and marketing. It is the main driver in tourism marketing also. The creation, aggregation and distribution of creative, innovative and engaging text, imagery and video are at the very core of successful ICT-based tourism marketing. Content-driven marketing is the most cost-efficient and effective form of marketing. However, content development is often the most troublesome component of a tourism marketing campaign. Planning ahead and thinking strategically can create long-term efficiencies in aggregating, developing and distributing content that will be used across all ICT-based tourism marketing platforms [10]. The four key features of a good content in context to tourism marketing are: Compelling, Trustworthy, Efficient and Accessible. Multimedia based ICT applications can generate good quality digital online as well as offline contents.

Website Management: In the digital era, Websites are the digital online storefronts for destinations and tourism business. Responsive and personalized design trends in website design are providing better responses in tourism marketing. However, adding a Blog to a website is an important factor in search engine optimization. Tourism website blogs are a key provider of dynamic content: $57 \%$ of companies with a blog have acquired a customer from their blog; $81 \%$ of business report that their company blog is useful to critical for their business [11].

Social Media (eWOM): Traditional Word to mouth marketing has transformed into eWOM or Electronic WOM. Social media is an extension of that. Any tourist will like to share their sweet tour experiences with their near and dear ones. Now, in this fast world, it is really tough to share the experiences face to face. They can share their experiences over the phone. But in that case they can't share the pictures or videos of the tour destination. Instead of sending or forwarding emails, the social media websites are providing a platform to share their experiences over the Web with any number of audiences they prefer. At the same time they can receive comments about their tour experiences from the uploaded photos or videos. The tourists are enjoying the comments or likes on their online shares, but unknowingly they are performing indirect marketing. So, if the tourist destination or the tour agents have provided a quality service, the social media shares are drawing the attention of future tourists for those tourist destinations. Facebook, Twitter, YouTube, Instagram etc. are few popular social websites where people can share online pictures, videos or other digital documents.

Web 2.0: "Web 2.0", a new name has been introduced to the Web technology. A website is no longer a static page in the browser, but a dynamic platform where the users can generate and update their own experiences. Another important aspect of this Web as platform is, these websites provide users the access to their data through well-defined user-friendly Application Programming Interfaces (APIs) and hence encourage new uses of that data, for example integrating personal data with other data sources. Geospatial Mashup is one of the most popular Web 2.0 technologies. It is a genre of interactive and collaborative Web applications under Web 2.0. It impeccably integrates heterogeneous datasets retrieved from varied Web-based resources to craft innovative Web GIS applications. It provides user-friendly platform to access up to date reliable information just on a click and at the same time, provides privilege to the users to share their local information to make it available globally over the Web [12].

\section{MASHUP ARCHITECTURE}

The concept of collaborative contribution for online systems leads to the new avenue of Geospatial science and technology called Geospatial Mashups. According to OGC (OGC, 2002), Web Feature Service is one of the most important web data service. It allows a client to retrieve heterogeneous geospatial data from multiple geospatial data servers. Using HTTP as the distributed computing platform it allows fundamental database Query operations like, Select, Update, Insert, Delete etc. The counterpart Web Map Service is defined by OGC (OGC, 2004) as the service that is capable of creating and projecting maps that come concurrently from different heterogeneous sources in any of the following standard image format, $S V G$, $P N G, G I F$, and JPEG.

Mashup: Web GIS initiated from a basic assumption that the global geo information cannot be captured saved and customized under a single organizational unit. The second group of authenticated end users can provide the up-to-date information and can be accessed globally. This concept of collaborative contribution for the system leads to the new avenue of Geospatial science and technology called Geospatial Mashups. The term "Mashup" is historically rooted in musical style compositions where recordings from different sources are combined into a new piece. On the Web it means taking information published from multiple sources and integrating it into a new information stream [8]. In Web GIS, geomashup is being used. A geomashup is a Mashup where at least one of the contents or functions is geo-referenced. Geospatial Mashups integrate multiple data sources based on common geographic locations. Mashups carry the overlay functions. In an overlay function, information from different heterogeneous sources are merged together and represented as a single informative Mashup layer. It includes topological overlay which restructures into a single vector dataset and a graphic overlay which superimpose images or maps on top of other. Most of today's online Mashups are graphic overlays.

Mashup Architecture: The two principal active components of Web Mashups are Data and Application Programming Interfaces (APIs). This provides an interface to allow nonprogrammers to access malleable form of data in a userfriendly environment. If the internet is thought of in superseding layers- physical (the wires), logical (the protocols), content and social- Mashups fit between the content and social layers, changing the way in which individuals relate to content [13]. Any typical Mashup follows a 3-tier architecture following a combination of client-server and Web service model. A general Mashup architecture consists of three different active components which are 
logically and physically disjoint. The generic architecture has the Mashup Client on the topmost view level and the physical data sources and services on the bottom level. The logical level is the intermediate level which helps in executing queries and retrieving the required data from the physical data layer. The logical execution may occur on the server or within the Web browser. Figure 2 represents the 3-tier Mashup architecture.

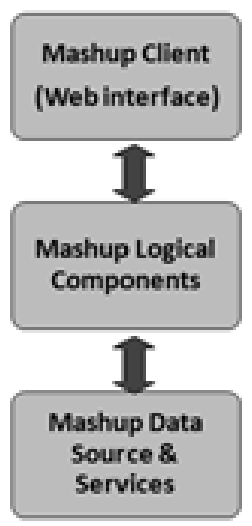

Fig. 2 Three-tier Mashup Architecture

Most of the today's online Mashups are graphic overlays. The simple architecture of Web GIS consists of a server end and client or browser end. The Mashup operation can be implemented in both the ends. If the Mashup operation is performed in the server end, it is called a Server-side Mashup. On the other hand, if it is performed on the client end it is called as Browser-side or Client-side Mashup. Servers act as a proxy between the Web browser in the client-end and the source website that is actively participating in the Mashup process. Figure 3 illustrates the Server-side Mashup architecture. In the client-side or browser-side Mashup the Web browser sends requests to different services, receives the responses and displays the composite results. The client-side Mashup architecture is illustrated in Figure 4. Client-side Mashups do not use a specific server that acts as proxy, but integrate different data and components with the client browser. The advantage of Server-side Mashups is that the server has more powerful hardware and software than the browser, but these Mashups also require specialized programming tools and complex-server side programming, which includes more manual work during development and deployment. Because of this complex programming and tedious work, the original Server-side Mashups were mainly limited to professional programmers.



Source: Adapted from java.sun.com

Fig. 3 Server-side Mashup Architecture

As a result of that, most of the today's Mashups are Browser or Client side [12]. It uses mainly lightweight programming; thus, it has become easy to develop. Professional GIS companies have adopted this approach as an easy and fast way to develop Web applications. ArcGIS by ESRI is one such example. 


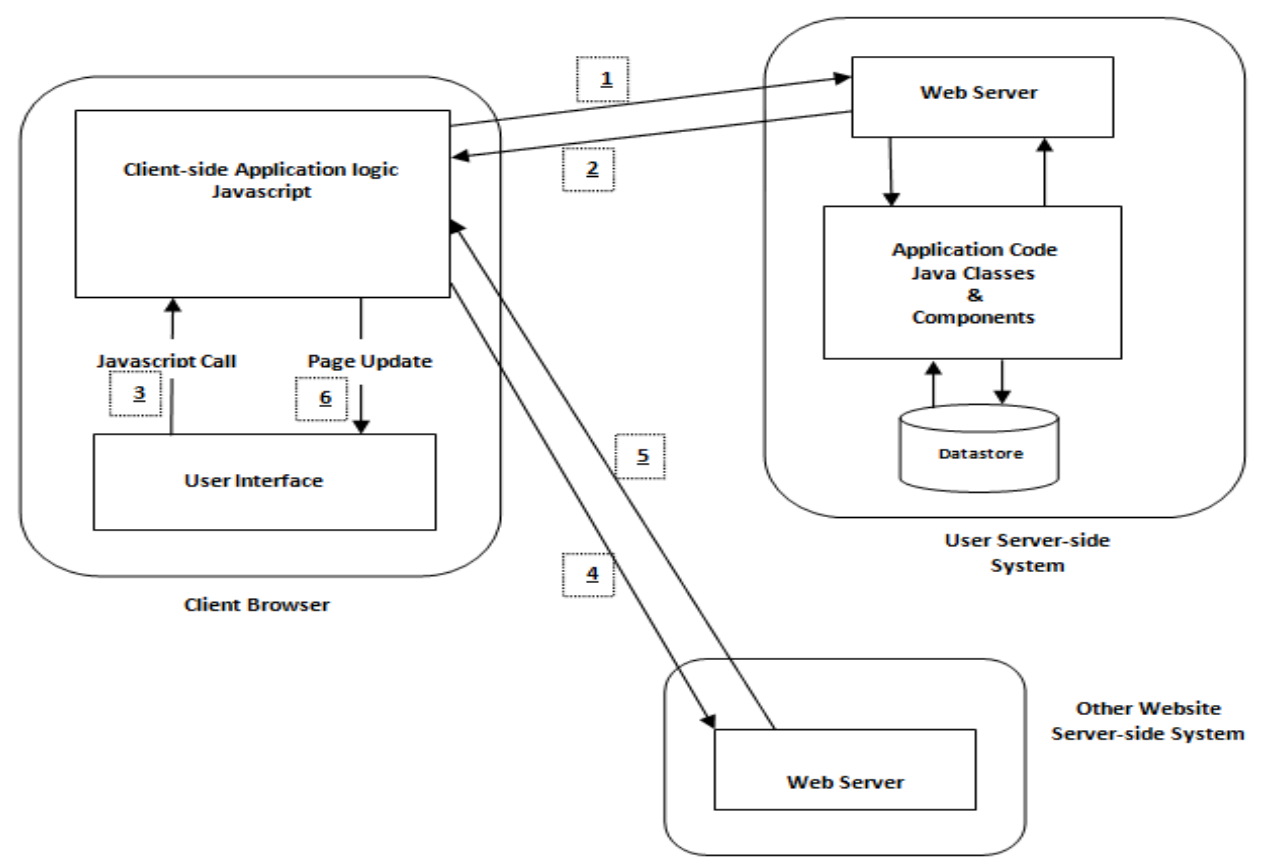

Source: Adapted from java.sun.com

Fig. 4 Client-side Mashup Architecture

\section{IMPLICATIONS OF GEOSPATIAL MASHUP IN TOURISM}

The ability to examine data in its spatial context is extremely important. The geocoding process takes a simple street address and matches it to a database containing address ranges for every link in the street network. In this way customer lists may be converted into simple dot maps, or coupled with census data and displayed as maps of market penetration [14]. This research paper concentrates mainly on the application of Geospatial Mashups in tourism sector. With respect to the tourism industry the map Mashup can be classified into four broad sections:

Informative Mashup: It is designed for information presentation like, Housing Maps, Road Maps etc. It deals mainly with one-way information flow.

Participatory Mashup: It focuses on "initiative participation" where people can add data content, initiate a participatory process, and interact with the content other people have added [8].

Collaborative Mashup: It in addition to the two-way participation, it also allows sharing of the data content and collaboration between users using maps as a platform. The collaboration can be either asynchronous or synchronous by remixing a real-time chat service, for example [8].

Enterprise Mashup: It can be any of the above three types or a combination of two or more.

\section{PICTORIAL EVIDENCE FOR APPLICATION OF GEOSPATIAL MASHUPS}

Figure 5 represents the base map of Male', the capital city of Maldives, one of the global hotspot tourist location. The current image is generated using Google Earth software without using any of the available Mashup layers provided by the software. Male' Presidential Palace, a place of interest in this tourist location has been kept on focus while designing the figure.

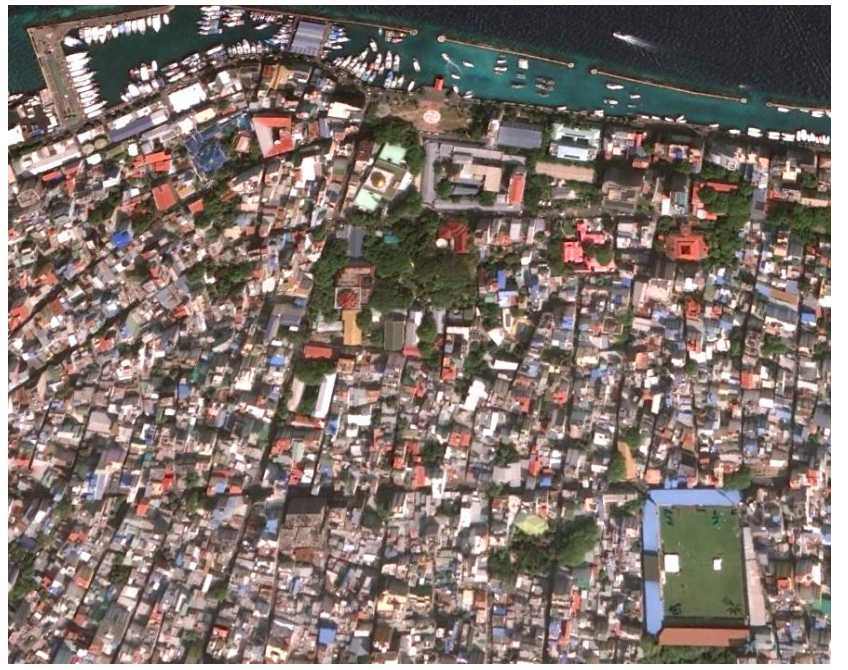

Image generated by using Google Earth software

(Source: https://www.google.mv/maps/)

Fig. 5 Base Map without Mashup Applications

In figure 5 no detailed information of the location has been specified. It is just an initial aerial imagery map having only the land structure and the roads. It is the Basemap. In the next step the Operational Layers other end users have implemented Participatory or Collaborative Mashups. Some users have supplied the information about the roads, bus stops, ferry service, hotels, restaurants, government sectors etc. Few others might have contributed in providing information about the local school, colleges, universities and health centres. There is high probability of receiving the data from different clients in heterogeneous form. When all these heterogeneous data is compiled and remixed, it results into this detailed map, 
containing detailed spatial information of the location. Figure 6 represents the Mashup interface of the same location. Figure 6 is the product of a Map Mashup application. If figure 5 and 6 are compared the utility of the Map Mashup system is selfexplanatory. In figure 5 only the base map is displayed. But in the next figure it contains detailed information about travel and transportation including specific roads and bus stops. As Maldives is an island country, the potential tourists need information about the water transport or the ferry service. The Mashup image contains the detailed information about the ferry terminals which was not available in the previous Basemap. On the other hand, it provides detailed information of hotels, resorts or restaurants including the amenities available and individual charge just one a click on specific hotel or restaurant name in the map. It also provides review report of tourists who have already been serviced by the specific hotels or restaurants. From the report the potential tourists can get an idea about the service and facilities available. Figure 6 is depicting the information of the tourist spot Presidential Palace of Male', Maldives. The specific location has received 4.7 star grades (out of 5) from the tourists or locals who have already visited the spot. It provides few uploaded photos. The potential tourists can view the reviews also just on a click. All these information are uploaded by different users most probably uploading platforms are heterogeneous.

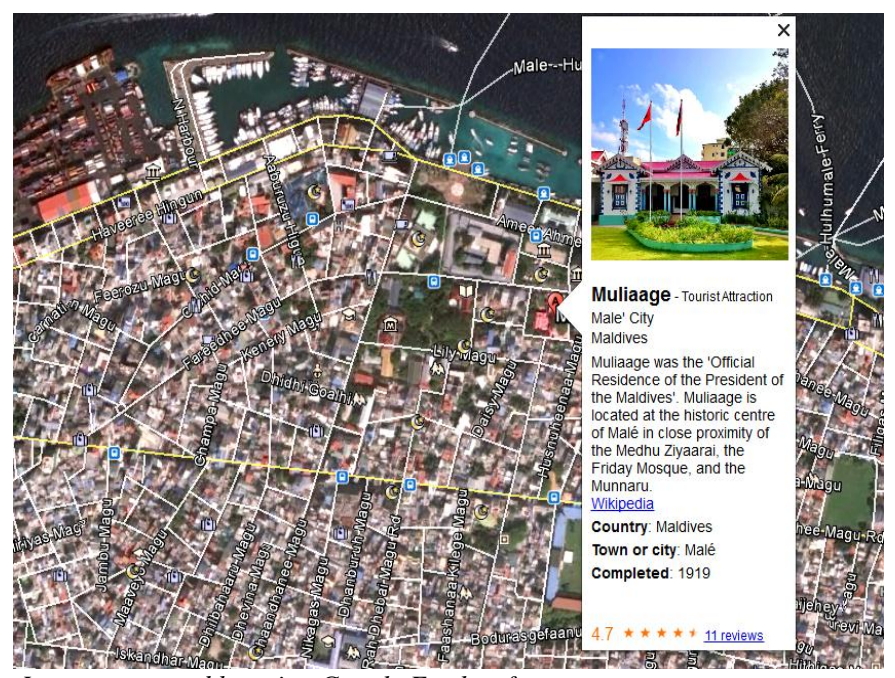

Image generated by using Google Earth software

(Source: https://www.google.mv/maps/)

Fig. 6 Mashup Map

But the effect is same online globally. Thus, this Mashup service is providing detailed information about a location in a collaborative manner. The basic information is required by a potential tourist to visit any tourist location. Initially, the tourists have to depend on the information provided by the travel agents about a location. The agents used to provide the information over telephonic conversation or sharing documents over email. The information may not be up-to-date and the tourists have to solely trust the agents. The tourists could have viewed the aerial imagery maps over the internet, but those maps don't provide detail information about the road, hotels, place of interest, transport facilities available etc.
But now with the detailed geospatial Mashup services over any Web GIS applications, the tourists can collect detail information about their place of choice. They have to just browse the internet, run the online Web GIS application and run a query [15]. They will receive detailed information about the location. Another greatest advantage in this Participatory or Collaborative Mashups is that, the globally accessible Geo Mashups are always up-to-date; they contain the most recent information about the location. Even the tourists while visiting those tourist sites if they found something is not matching with the Mashup information over the internet, they can customize those global information with the updated one. This will be beneficial for other potential tourists. These are the benefits of updating information of those locations which are already established as tourist spots. Now, if some entrepreneur or travel agency wants to project a new location as a tourist spot, they can perform initial research work to analyze whether their local area can be developed as a potential tourist destination or not. First and foremost, they have to find out whether that particular location has any Cultural, Ecological or Modern tourism component or not. If it is there they can update that information using the Mashup option in Web GIS application. Next, they have to update other facilities like, transport, hotels, café, health service etc. even internet facilities available or not. That means, the locations which can be potential tourist spots can slowly come into limelight just by some simple initiatives taken by the locals. One such online application provided by Google is http://editor.giscloud.com/ where the end users can update and create map online contributing detailed information about their locality or any other place of interest. In this way the Geospatial Mashups are making hundreds of new Cultural, Ecological or Modern tourist locations popular. This is effecting overall economic development of the location through tourism industry [12]. On the other hand, in today's competitive marketplace, leading companies are analyzing and listening what customers really care about. Traditional forms of marketing are no longer as effective as they used to be in the past. This is where Web GIS comes in and allowing the companies to visualize where potential customers are located by analyzing demographic, psychographic, purchasing, and spending characteristics for accurate customer segmentation and helping the companies to find more like them [16]. The tourism sector is implementing the Web GIS Mashup application as a promotional and marketing tool.

\section{MASHUP POTENTIAL IN TOURISM MARKETING}

The ability to examine data in spatial context is significantly important. A simple name or few attributes of a customer conveys very little. But if the address of the customer is depicted in an online map then that particular customer can be related to the known characteristics of the neighborhood. The geocoding process in a geospatial application will track the exact location in a map, which may lead to important marketing findings like, the economic standard of the locality, other shopping alternatives, banking facility, transport facility etc. In this way potential customer lists can be converted into simple dot maps and displayed as interactive maps of market penetration. A map is a static representation of data which is 
efficient in exploring geographical distributions and specific spatial relationships [12].

Exploratory Spatial Analysis (ESA): If the dataset is complex, then the single perspective presented by a map might not be that effective. Recently, there have been various significant efforts to use Geospatial Mashups or Map Mashups in particular to provide market analysts with spatial tools for exploring geographical markets. Geospatial Mashups can be effectively implemented as exploratory spatial tools. The greatest advantage of ESA is that, it can help in avoiding the high cost of transporting one or more specialists or analysts to the original site. Instead the analysts can make a virtual tour just on a click and can make important analysis and assessments. Another important ESA application is in business site selection.

Value-added Marketing: The term value added marketing defines the value that is added to a product or a service as a result of a particular process or the increase in value of a product or service as a result of a particular activity. In the context of marketing, the activity might be packaging or branding. The new ways of presenting products and services on the internet offer new possibilities for value-added marketing [17]. Few effective of them are as follows:

Mouse over-ads: Defined keywords with more information are highlighted in any online content of a website. When the mouse is hovered on that particular keyword it displays marking information.

Tagvertising: Combines traditional websites with tagging websites where anyone can book a particular tag that will later be displayed in the main tag cloud at the website [17].

Geo-tagging and Geo-locating: It is the process of combining geographical information with static website content. It acts as a bridge between the online and offline world. The website www.eatolls.com contains the detailed Mashup information about the atolls of Maldives. Figure 7 depicts the Mashup site when the search element is Island.

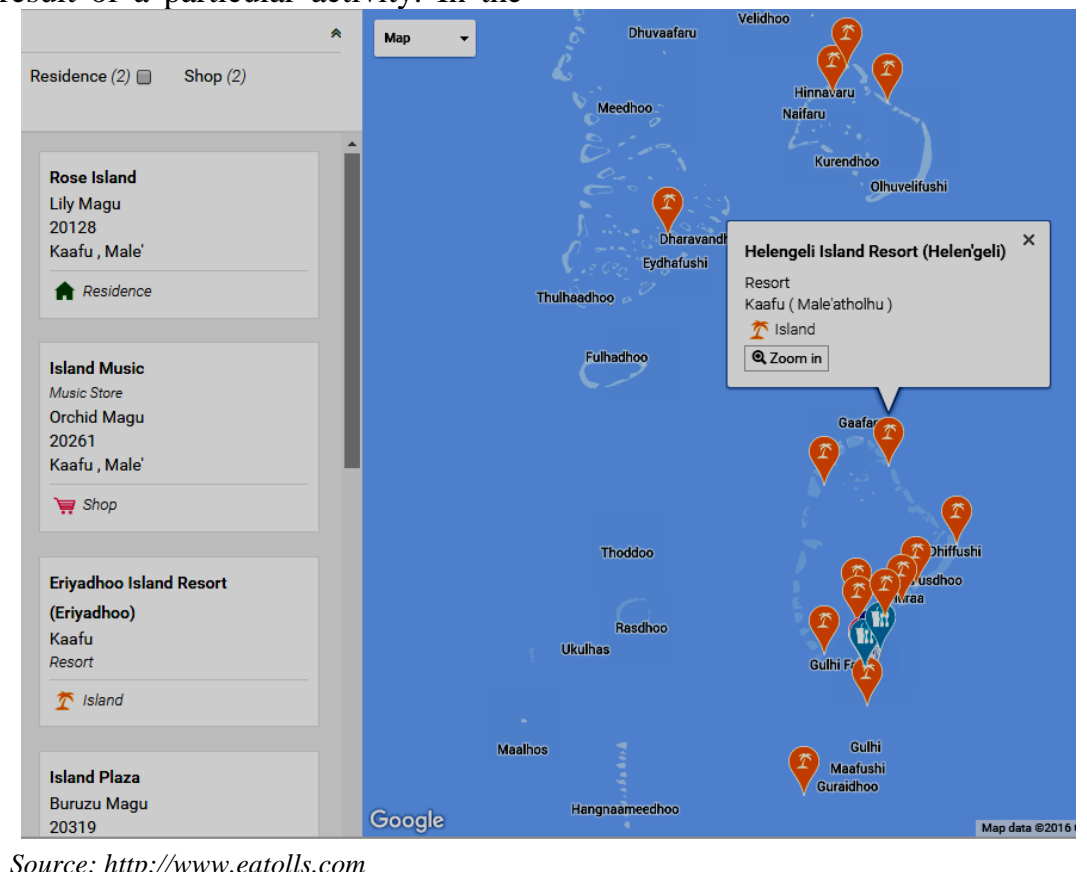

Fig. 7 Example of Geo-tagged Website in Maldives

Recently a very popular application on the Web 2.0 is the online geo-tagging of photos. Any web user can upload their personal clicks; the photos can be commented, viewed and shared with the integrated geo-tagged portals. In the above figure the image of a specific café is geo-tagged in the website and the other café are highlighted in the Mashup map. On click they can provide detailed information like address, contact numbers etc.

Mashup-ads: Mashup-ads are dynamic display ads that change when the content changes. The ad takes content from a publisher's site and mashes it up with content from an advertiser's site, creating an ad relevant to the user's browsing experience. Mashup-ads not only bring content into the ad, but they can bring site functionality as well [17].

Tourism being a service industry can also customized by careful implementation of Geospatial or Map Mashups. It can be effectively applied for tourism promotion as well as for overall tourism management and development. Initially when Web 2.0 was not into play in internet technology, the main problem of this service industry was information sharing. The potential tourists have to trust the information provided by the tourism companies or agents. In some cases, information shared by the tourism councils of few locations was also not trustworthy. This information was not regularly updated or customized. The tourism agencies were also having tough time to plan for any tourism promotion or marketing strategy. But with the introduction of Web 2.0 these problems started fading away [18]. Slowly, Web GIS became one of the principal strategic decision making tool in e-business. In tourism industry, Web GIS is the information system that provides functions including visual presentation about the tourism destination, advanced analysis, etc., of digital geospatial 
information by processing it in an integrated manner on electronic maps of the tourist site [1].

\section{CONCLUSION}

Mashups provide different opportunities for sharing data collaboratively and using information in new applications and systems. Like all other technologies Mashup also has few challenges and demerits. New research works are going on to address the following drawbacks of Mashups:

Classifying Map Mashups, Quality and Reliability of Information, Copyright and Ownership Issues, Security Issues, Technical Challenges, Limited application in E-Government. In spite of the drawbacks, it has become an integral design pattern for Web GIS applications. The basic advantages of Mashup applications are:

Applicability: Mashup is providing the platform where heterogeneous data can be shared and incorporated together. So, the tools are useful for varied areas and can support a great variety of input and output data types.

Ease of use: The information is shared globally in the Mashup. Anyone can view the information just on a click. On the other hand, the graphical user interface is designed in such a way that any non-technical user can also comment or add new information.

Interoperability: Different tools can be easily incorporated together in the Mashup applications. Like in QGIS (a free Web GIS software), plugin Google or Bing Maps can be easily combined.

Reusability and extensibility: The uploaded modified Mashup maps are specially designed for sharing and reusing.

Collaboration: This is the best feature that any online application should have. Active participation from all level of users facilitates the improvement of applications much faster than the traditional methods.

Serious research works and well planned implementation of geospatial Mashups, especially in the domain of collaborative and interactive map Mashups for e-government services and enterprise information management will lead a long way towards strategic interactive and participatory decision making system in tourism promotion and management. Future research scope of this present paper depicts few programmability, security and scalability issues which require a room for future improvement.

\section{ACKNOWLEDGMENT}

We would like to thank Mr. MOHAMED IRFAN AHMED, Mr. IBRAHIM AZHAD AND MR. JAWAD (eatolls, Male', Republic of Maldives) for giving their consent to include the snapshot of their website http://www.eatolls.com/. Although any errors are our own and should not tarnish the reputations of these esteemed persons.

\section{REFERENCES}

[1] S. Chaudhuri, N. Ray, "Application of Web-Based Geographical Information System (GIS) In Tourism Development," Encyclopedia of Information Science and Technology, IGI-Global, 3rd ed., 2015, pp. 7026-7036.

http://dx.doi.org/10.4018/978-1-4666-5888-2.ch692
[2] D. Buhalis, "Strategic use of information technologies in the tourism industry," in Tourism Management, 19th ed. vol. 5, 1998, pp. 409-421.

[3] T. Pierce, G. Dobson and M. Phillips, "GIS Mashups on the Web: Using Google, ESRI, and Open Source to Develop Weather and Climate Applications for the Web," in Conf. Geospatial Infrastructure Solutions, Tampa FL, Apr. 2009

[4] P. Fu and J. Sun, Web GIS, Principles and Applications, ESRI Press, Ed. 1, pp. 25-45, pp. 89-114

[5] V. F. Balogun, A.F. Thompson and O.A. Sarumi, "A 3D Geo-Spatial Virtual Reality System for Virtual Tourism," in The Pacific Journal of Science and Technology, 11th ed. vol 2, 2010, pp. 601-609

[6] M.T. Linaza, F. Lolhoffel, A. Garcia, C. Lamsfus, A. A. Sorzabal and A. Lazkano, "Mash-up applications for small Destination Management Organizations web sites," in Information and Communication Technologies in Tourism 2008, Springer-Verlag, 2008, pp. 130-140

[7] C. T. Alonso, S. Fern'andez, D. Berrueta, L.Polo, M. J. Fern'andez, and V. Morlan, "eZaragoza, A Tourist Promotional Mashup," in Conf. AI Mashup Challenge 2010, co-located with the 7th Extended Semantic Web Conference, ESWC, Heraklion, Greece, 2010

[8] S. Li and J. Gong, "MASHUP: A New Way of Providing Web Mapping/GIS Services," The International Archives of the Photogrammetry, Remote Sensing and Spatial Information Sciences, XXXVII ed. vol. B4, 2008, pp. 639-648

[9] R. Lagiewski and B. Zekan, "Experiential marketing of tourism destinations," in Proc. the Turk - Kazakh International Tourism Conference Detay Yayincilik Ltd, 2006

[10] COMCEC Coordination Office, "Effective Tourism Marketing Strategies: ICT-Based Solutions for the OIC Member Countries", Retrieved

from http://www.mod.gov.tr/Lists/RecentPublications/Attachments/85/Effecti ve_Tourism_Marketing_Strategies,_ICT-

Based_Solutions_for_the_OIC_Member_Countries.pdf on 10 Jan. 2016

[11] M. K. Anderson, "How to Use Dynamic Content for "smarter" Marketing Hubspot Blog," Retrieved from http://blog.hubspot.com/marketing/how-to-use-dynamic-smart-contentim-ht on 20 Dec. 2015

[12] S. Chaudhuri, "Potential of Geospatial Mashups for Tourism Marketing," in Tourism: Marketing A Strategic Approach, Apple Academic Publisher, to be published

[13] J. Palfrey and U. Gasser, "Mashups Interoperability and eInnovation. Case Study," in Berkman Publication Series, Harvard University Research Center of Information Law and University of St. Gallen, 2007

[14] M.F. Goodchild, "ILACS: A Location-Allocation Model for Retail Site Selection," in Journal of Retailing, ed. 60, 1984, pp. 84-100

[15] S. Chaudhuri and N. Ray, "Geospatial Mashups in Web GIS for Tourism Infrastructure: Internet Based Channel Perspective Promotional Measures," in Business Infrastructure for Sustainability in Developing Economies, IGI Global, USA, to be published

[16] A. Auinger, H. Konnerth and N. Dietmar, "Potential of Web-Mashups for Marketing 2.0 Wehrgrabengasse 1-3," 4400 Steyr, Austria, 2008

[17] ESRI, "GIS for Marketing: Where Strategy Meets Opportunity (2010)," Retrieved from http://www.esri.com/marketing on 10 Dec. 2015

[18] N. Ray, D. K. Das, S. Chaudhuri, "Tourism Promotion through Web," in Strategic Marketing in Fragile Economic Condition, IGI Global, USA, 2014, pp. 237-247

http://dx.doi.org/10.4018/978-1-4666-6232-2.ch013 